\title{
Distinguishing Self-Assembled Pyrene Structures from Exfoliated Graphene
}

Maxim Varenik, ${ }^{* \dagger}$ Micah J. Green, ${ }^{\S}$ and Oren Regev ${ }^{\dagger, \ddagger}$

${ }^{\dagger}$ Department of Chemical Engineering and ${ }^{\ddagger}$ Ilse Katz Institute for Nanoscale Science and Technology, Ben-Gurion University of the Negev, Beer-Sheva 8410501, Israel

${ }^{\S}$ Artie McFerrin Department of Chemical Engineering, Texas A\&M University, College Station, Texas 77843-3122, United States

\section{Corresponding Author}

*(M.V.) E-mail max.varenik@gmail.com
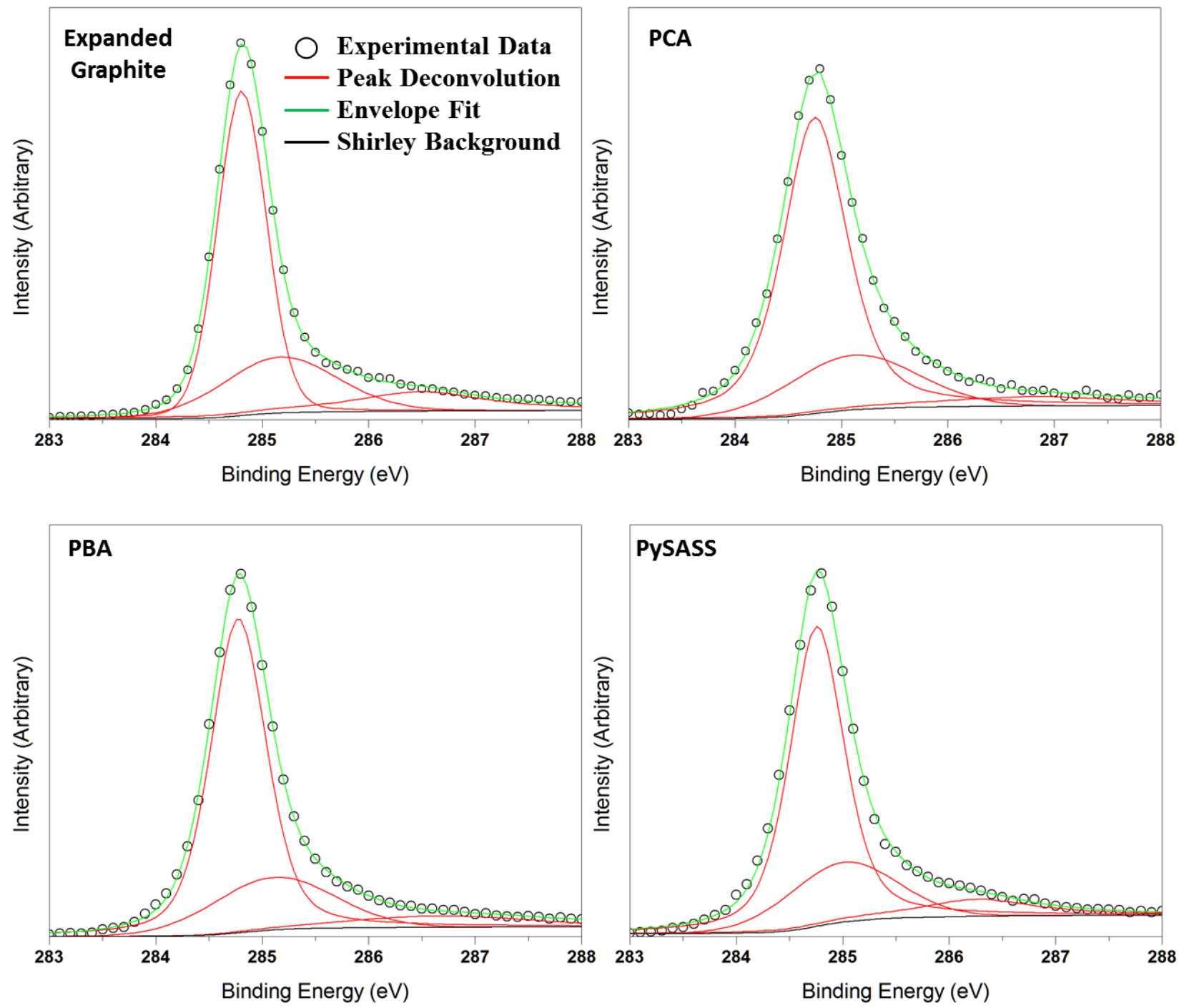
Figure S1. XPS spectra deconvolution of expanded graphite and graphene dispersions prepared with PySASS, PBA, and PCA after rinsing. Deconvolution was performed by least square fitting in MATLAB, to a Voight profile. Peak data is given in table 1.

Table S1. Peak parameters for deconvolution in Figure S1.

\begin{tabular}{llllllllll}
\hline & \multicolumn{3}{c}{ Peak 1 $(\mathrm{C}=\mathrm{C})$} & \multicolumn{3}{c}{ Peak 2 $(\mathrm{C}-\mathrm{C})$} & \multicolumn{3}{c}{ Peak 3 (C-O) } \\
\hline & Center & Width & Area Ratio & Center & Width & Area Ratio & Center & Width & Area Ratio \\
\hline Expanded Graphite & 284.8 & 0.5 & 1 & 285.2 & 1.3 & 0.4 & 286.5 & 1.5 & 0.2 \\
\hline PCA & 284.8 & 0.7 & 1 & 285.1 & 1.4 & 0.3 & 286.8 & 2.2 & 0.1 \\
\hline PBA & 284.8 & 0.6 & 1 & 285.1 & 1.3 & 0.3 & 286.7 & 2.0 & 0.1 \\
\hline PySASS & 284.8 & 0.6 & 1 & 285.1 & 1.2 & 0.3 & 286.4 & 1.4 & 0.1 \\
\hline
\end{tabular}

